\title{
An empirical study on entrepreneurs' personal characteristics
}

\author{
Ahmad Ahmadkhani*, Mehrnaz Paknezhad and Arezo Nazari
}

Sama Technical Vocational Training College, Islamic Azad University, Zanjan Branch, Zanjan, Iran

\begin{tabular}{|c|c|}
\hline ART I C L E I N F O & A B S T R A T \\
\hline $\begin{array}{l}\text { Article history: } \\
\text { Received June 15, } 2011 \\
\text { Received in Revised form } \\
\text { October, 12, } 2011 \\
\text { Accepted 15 December } 2011 \\
\text { Available online } \\
5 \text { January } 2012 \\
\text { Keywords: } \\
\text { Entrepreneurship } \\
\text { Personality } \\
\text { Job creation } \\
\text { Creativity }\end{array}$ & $\begin{array}{l}\text { The personality of an entrepreneur is one of the most important characteristics of reaching } \\
\text { success by creating jobs and opportunities. In this paper, we demonstrate an empirical study on } \\
\text { personal characteristics of students who are supposed to act as entrepreneur to create jobs in } \\
\text { seven fields of accounting, computer science, mechanical engineering, civil engineering, } \\
\text { metallurgy engineering, electrical engineering and drawing. There are seven aspects of } \\
\text { accepting reasonable risk, locus of control, the need for success, mental health conditions, } \\
\text { being pragmatic, tolerating ambiguity, dreaming and the sense of challenging in our study to } \\
\text { measure the level of entrepreneurship. We uniformly distribute } 133 \text { questionnaires among } \\
\text { undergraduate students in all seven groups and analyze the results based on t-student test. Our } \\
\text { investigation indicates that all students accept reasonable amount of risk, they preserve } \\
\text { sufficient locus of control and they are eager for success. In addition, our tests indicate that } \\
\text { students believe they maintain sufficient level of mental health care with strong sense of being } \\
\text { pragmatic and they could handle ambiguity and challenges. }\end{array}$ \\
\hline
\end{tabular}

(C) 2012 Growing Science Ltd. All rights reserved.

\section{Introduction}

Today, there is no doubt that people with great personality are best candidates of being successful entrepreneurs in different fields from information technology to other industries. There are many dedicated people like Steve Jobs, who contribute all their lives to create value added products even one day before they die. These people leave a cultural heritage among our nations and give many moral stories. The primary concern with most of these people is that they have special characteristics to sacrifice their best times on what they were planning to create. People like Bill Gates spent all their personal times including their weekend to build a remarkable product such as Windows operating system, which would benefit literally billions of people round the world.

Personality is one of the most components of entrepreneurs and in many cases, this is the main criterion to decide whether an entrepreneur is entitled to receive financial assistance or not. In fact, many banks' officials, venture capitals make financing decision solely based on the interview on entrepreneurs' personal characteristics. During the past few decades, there have been tremendous efforts on detecting important factors on the success of an entrepreneur.

\footnotetext{
* Corresponding author. Tel: + 09358799109

E-mail addresses: adahmadkhani@gmail.com (A. Ahmadkhani) 
Khorshidifar and Abedi (2010) presented an empirical study on the impact of stress on the relationship between locus of control and job satisfaction and job performance. The study selected a sample size of 65 senior and regular accountants who worked for thirteen different regional municipalities of city of Mashad located in east part of Iran. The study applied various well-known questionnaire methods such as stress diagnostic survey, locus of control, job satisfaction and employees' performance to perform the study. The results indicated that the stress was on average level for the dominant locos of control factors and job satisfaction and employee performance are in relatively high level. The study also disclosed that there were four important factors of role of ambiguity, quantitative overload, career development and handling other workers' responsibilities play important role on job satisfaction and managing career development has important impact on the performance of accountants.

Nicholson (1998) examined the question of whether there is an entrepreneurial leadership personality profile using an empirical investigation of the heads of the UK's top independent companies and comparing them with sample norms and a management control group. Wijbenga and van Witteloostuijn (2007) studied the impact of environmental dynamism on entrepreneurial locus of control-competitive strategy relationship and reported that internal entrepreneurs prefer product innovation strategies in stable environments, whereas external entrepreneurs opt for low-cost strategies in dynamic environments. Zampetakis (2008) studied the role of creativity and proactivity on perceived entrepreneurial desirability.

Zhou (2007) presented a comprehensive study on the effects of entrepreneurial proclivity and foreign market knowledge on early internationalization. Brush et al. (2009) introduced pathways to entrepreneurial growth by investigating the influence of management, marketing and money. They reported that fast-growing companies exhibit different rates and patterns of growth: some represent fast growth trajectories; some, slower, more measured rates; others, episodic periods of quick growth followed by sharp retrenchment. They also found that three key factors - management, marketing, and money-affected company growth across these patterns. Obschonka et al. (2010) explained that entrepreneurial intention is the key success for new ideas. Ucbasaran et al. (2010) presented a study on the nature of entrepreneurial experience, business failure and comparative optimism. Lin (2006) presented a comparative study on the trends of entrepreneurial behaviors of enterprises in different strategies. Schmitt-Rodermund (2004) introduced four aspects of parenting, personality, early entrepreneurial competence, and interests for the success of entrepreneurship. She reported an early start-up and an entrepreneurial personality of the founder as important factors. She reported on implications of her findings, which are bank professionals dealing with venture capital loans.

In this paper, we present an empirical study to measure different entrepreneurship characteristics of students who study in various educational fields. The study designs a questionnaire based on different criteria such as locus of control, need for success, dream, challenge, etc. The organization of this paper is as follows. We first present details of our questionnaire in section 2 and the results of our analysis are discussed in section 3. Finally, concluding remarks are given in the last to summarize the contribution of this paper.

\section{Problem statement}

In this paper, we select all students who were studying in different fields of accounting(AC), computer science(CS), electrical engineering (EE), mechanical engineering(ME), civil engineering(CE), metalorgy(MR) and drawing(DR). The sample size is calculated as follows,

$$
n=\frac{N \times z_{\alpha / 2}^{2} \times p \times q}{\varepsilon^{2} \times(N-1)+z_{\alpha / 2}^{2} \times p \times q},
$$


where $N$ is the population size, $p=1-q$ represents the yes/no categories, $z_{\alpha / 2}$ is CDF of normal distribution and finally $\varepsilon$ is the error term. Since we have $p=0.5, z_{\alpha / 2}=1.96, \varepsilon=0.03$ and $N=1012$, the number of sample size is calculated as $n=133$. The questionnaire was designed based on Likert scale (Likert, 1932) from completely agree to completely disagree in four different scales. In our study, 72.2 percents of the participants were young people aged 18 to 22, 20.3 percents of them were between 23 to 28 and only 7.5 percents were between 29 and 36 years old. The questionnaires were equally distributed among seven groups of students who were involved in various fields of accounting, electronic, drawing, civil, metallurgy, mechanical and computer engineering. In terms of gender, 70.9 percents of the participants were male and 29.1 percents were female students. In terms of personal skills, 49.3 percents replied positively and the rest of them representing 50.7 percents claimed they had no personal skills. In terms of being motivated for setting up a small business, 40.3 percents responded yes and 59.7 percents responded no. The proposed study of this paper considers the following eight hypotheses,

1. Students accept reasonable amount risk (ARR).

2. Students have desirable level of locus of control (LOC).

3. Students have desirable level of reaching prosperity and success (NFS).

4. Students are in good mental health conditions (MHC).

5. Students are pragmatic (P).

6. Students could handle a good level of ambiguity (HA).

7. Students have desirable level of dreaming (D).

8. Students could handle challenges in their life (C).

\section{Results}

In this section, we present details of our finding on eight hypotheses.

\subsection{Accepting desirable level of risk}

The first hypothesis is associated with the level of risk they could accept.

$\begin{cases}H_{0}: & \text { Students do not accept sufficient level of risk } \\ H_{1}: & \text { Students accept sufficient level of risk }\end{cases}$

Table 1 shows details of our finding,

\section{Table 1}

The results of t-student for ARR

\begin{tabular}{lccc}
\hline Hypothesis & t-student & Degree of freedom & P-value \\
\hline 1 & -21.706 & 18 & 0.000 \\
\hline
\end{tabular}

As we can observe from the results of Table 1, we have a meaningful level of t-student, which means we can reject the null hypothesis. Therefore, we can conclude that students who are presently educating in this school accept a reasonable amount of risk.

\subsection{Locus of control}

The second hypothesis is associated with the locus of control.

$\left\{H_{0}\right.$ : Students do not have desirable locus of control

$\left\{H_{1}\right.$ : Students have desirable locus of control 
Table 2 demonstrates details of our test,

\section{Table 2}

The results of t-student for LOC

\begin{tabular}{lccc}
\hline Hypothesis & t-student & Degree of freedom & P-value \\
\hline 1 & -24.907 & 18 & 0.000 \\
\hline
\end{tabular}

As we can observe from the results of Table 2, we see a desirable value for t-student, which means we can reject the null hypothesis, leading us to claim that students who are presently educating in the school maintain sufficient locus of control.

\subsection{Motivation of having prosperity and success}

The third hypothesis is associated with their wish to reach prosperity and success.

$\begin{cases}H_{0}: & \text { Students do not have good motivation to reach prosperity and success } \\ H_{1}: & \text { Students wish to reach prosperity and success }\end{cases}$

Table 3 demonstrates details of our test,

Table 3

The results of t-student for NFS

\begin{tabular}{lccc}
\hline Hypothesis & t-student & Degree of freedom & P-value \\
\hline 1 & -26.589 & 18 & 0.000 \\
\hline
\end{tabular}

As we can observe from the results of Table 3, we see reasonably high value for t-student, which means we can reject the null hypothesis and conclude that students who are presently educating in the school wish to reach prosperity and success in their carrier and lives.

\subsection{Having sufficient health care}

The fourth hypothesis is associated with their mental health care (MHC).

$\begin{cases}H_{0}: & \text { Students do not have good mental health care } \\ H_{1}: & \text { Students have good mental health care }\end{cases}$

Table 4 demonstrates details of our test,

\section{Table 4}

The results of t-student for MHC

\begin{tabular}{lccc}
\hline Hypothesis & t-student & Degree of freedom & P-value \\
\hline 1 & -27.228 & 18 & 0.000 \\
\hline
\end{tabular}

As we can observe from the results of Table 4, t-student is highly meaningful, which means we can reject the null hypothesis and conclude that students who are presently educating in the school have sufficient level of mental health care.

\subsection{Being pragmatic}

The fifth hypothesis is associated with their sense of being pragmatic (P).

$\begin{cases}H_{0}: & \text { Students are not pragmatic } \\ H_{1}: & \text { Students are pragmatic }\end{cases}$

Table 5 demonstrates details of our test, 
Table 5

The results of t-student for being pragmatic

\begin{tabular}{lccc}
\hline Hypothesis & t-student & Degree of freedom & P-value \\
\hline 1 & -26.864 & 18 & 0.000 \\
\hline
\end{tabular}

As we can observe from the results of Table 5, t-student is highly meaningful, which means we can reject the null hypothesis and conclude that students who are presently educating in the school are pragmatic.

\subsection{Handling ambiguity}

The sixth hypothesis is associated with their sense of handling ambiguity (HA)

$H_{0}$ : $\quad$ Students are not able to handle ambiguity

$H_{1}$ : $\quad$ Students are able to handle a sufficient level of ambiguity

Table 6 demonstrates details of our test,

Table 6

The results of t-student for handling ambiguity

\begin{tabular}{lccc}
\hline Hypothesis & t-student & Degree of freedom & P-value \\
\hline 1 & -26.627 & 18 & 0.000
\end{tabular}

As we can observe from the results of Table 6, t-student is highly meaningful, which means we can reject the null hypothesis and conclude that students who are presently educating in the school are able to handle ambiguity.

\subsection{Dreaming}

The seventh hypothesis is associated with their sense of dreaming (D)

$H_{0}$ : $\quad$ Students do not have sufficient level of dreaming

$H_{1}$ : $\quad$ Students have sufficient level of dreaming

Table 7 demonstrates details of our test,

Table 7

The results of t-student for handling sufficient level of dreaming

\begin{tabular}{lccc}
\hline Hypothesis & t-student & Degree of freedom & P-value \\
\hline 1 & -26.163 & 18 & 0.000 \\
\hline
\end{tabular}

As we can observe from the results of Table 7, t-student is highly meaningful, which means we can reject the null hypothesis and conclude that students who are presently educating in the school maintain a good level of dreaming.

\subsection{The Handling possible challenges (C)}

The eighth hypothesis is associated with their sense of handling possible challenges (C)

$\left\{H_{0}\right.$ : Students cannot handle possible challenges with their jobs

$H_{1}: \quad$ Students can handle challenges with their jobs

Table 8 demonstrates details of our test,

\section{Table 8}

The results of t-student for handling possible challenges

\begin{tabular}{lccc}
\hline Hypothesis & t-student & Degree of freedom & P-value \\
\hline 1 & -26.265 & 18 & 0.000 \\
\hline
\end{tabular}


As we can observe from the results of Table 8, t-student is highly meaningful, which means we can reject the null hypothesis and conclude that students who are presently educating in the school can handle possible challenges in their jobs, properly.

\section{Conclusion}

In this paper, we have demonstrated an empirical study on personal characteristics of students who are supposed to act as entrepreneur to create jobs in seven fields of accounting, computer science, mechanical engineering, civil engineering, metallurgy engineering, electrical engineering and drawing. There were seven aspects of accepting reasonable risk, locus of control, the need for success, mental health conditions, being pragmatic, tolerating ambiguity, dreaming and the sense of challenging in our study to measure the level of entrepreneurship. We have uniformly distributed 133 questionnaires among undergraduate students in all seven groups and analyzed the results based on tstudent test. The results confirmed that all students accept reasonable amount of risk, they preserve sufficient locus of control and they are eager for success. In addition, our tests indicate that students believe they maintain sufficient level of mental health care with strong sense of being pragmatic and they could handle ambiguity and challenges.

\section{References}

Brush, C.G., Ceru, D.J., \& Blackburn, R. (2009). Pathways to entrepreneurial growth: The influence of management, marketing, and money. Business Horizons, 52(5), 481-491.

Cronbach, L. J. (1951). Coefficient alpha and the internal structure of tests. Psychometrika, 16(3), 297-334.

Friedman, M. (1940). A comparison of alternative tests of significance for the problem of m rankings. The Annals of Mathematical Statistics, 11 (1), 86-92.

Khorshidifar, M., \& Abedi, A. (2010). An empirical study on the impact of stress on the relationship between locus of control and job satisfaction and job performance. Management Science Letters, 4(1), 511-516.

Likert, R. (1932). A Technique for the Measurement of Attitudes. Archives of Psychology, 140, 1-55.

Lin, W.B. (2006). A comparative study on the trends of entrepreneurial behaviors of enterprises in different strategies: Application of the social cognition theory. Expert Systems with Applications, 31(2), 207-220.

Nicholson, N. (1998). Personality and entrepreneurial leadership: A study of the heads of the UK's most successful independent companies. European Management Journal, 16(5), 529-539.

Obschonka, M., Silbereisen, R. K., Schmitt-Rodermund, E. (2010). Entrepreneurial intention as developmental outcome. Journal of Vocational Behavior, 77(1), 63-72.

Schmitt-Rodermund, E. (2004). Pathways to successful entrepreneurship: Parenting, personality, early entrepreneurial competence, and interests. Journal of Vocational Behavior, 65(3), 498-518.

Ucbasaran, D., Westhead, P., Wright, M., \& Flores, M. (2010).The nature of entrepreneurial experience, business failure and comparative optimism. Journal of Business Venturing, 25(6), 541555.

Wijbenga, F.H., \& van Witteloostuijn, A. (2007). Entrepreneurial locus of control and competitive strategies - The moderating effect of environmental dynamism. Journal of Economic Psychology, 28(5), 566-589.

Zampetakis, L.A. (2008).The role of creativity and proactivity on perceived entrepreneurial desirability. Thinking Skills and Creativity, 3(2), 154-162.

Zhou, L. (2007). The effects of entrepreneurial proclivity and foreign market knowledge on early internationalization. Journal of World Business, 42(3), 281-293. 